\title{
The use of bluetooth low energy Beacon systems to estimate indirect personal exposure to household air pollution
}

\author{
Jiawen Liao' ${ }^{1}$ John P. McCracken ${ }^{2} \cdot$ Ricardo Piedrahita $^{3} \cdot$ Lisa Thompson $^{1,4} \cdot$ Erick Mollinedo $^{2} \cdot$ Eduardo Canuz $^{2}$. \\ Oscar De Léon ${ }^{2}$ - Anaité Díaz-Artiga ${ }^{2}$ - Michael Johnson ${ }^{3} \cdot$ Maggie Clark $^{5}$ - Ajay Pillarisetti ${ }^{6}$ - Katherine Kearns ${ }^{7}$. \\ Luke Naeher $^{7} \cdot$ Kyle Steenland ${ }^{1} \cdot$ William Checkley $^{8,9} \cdot$ Jennifer Peel $^{5} \cdot$ Thomas F. Clasen $^{1} \cdot$ HAPIN investigators
}

Received: 21 February 2019 / Revised: 9 July 2019 / Accepted: 25 July 2019

(c) The Author(s) 2019. This article is published with open access

\begin{abstract}
Household air pollution (HAP) generated from solid fuel combustion is a major health risk. Direct measurement of exposure to HAP is burdensome and challenging, particularly for children. In a pilot study of the Household Air Pollution Intervention Network (HAPIN) trial in rural Guatemala, we evaluated an indirect exposure assessment method that employs fixed continuous $\mathrm{PM}_{2.5}$ monitors, Bluetooth signal receivers in multiple microenvironments (kitchen, sleeping area and outdoor patio), and a wearable signal emitter to track an individual's time within those microenvironments. Over a four-month period, we measured microenvironmental locations and reconstructed indirect $\mathrm{PM}_{2.5}$ exposures for women and children during two 24-h periods before and two periods after a liquefied petroleum gas (LPG) stove and fuel intervention delivered to 20 households cooking with woodstoves. Women wore personal $\mathrm{PM}_{2.5}$ monitors to compare direct with indirect exposure measurements. Indirect exposure measurements had high correlation with direct measurements $(n=62$, Spearman $\rho=0.83$, $\mathrm{PM}_{2.5}$ concentration range: $5-528 \mu \mathrm{g} / \mathrm{m}^{3}$ ). Indirect exposure had better agreement with direct exposure measurements (bias: $-17 \mu \mathrm{g} / \mathrm{m}^{3}$ ) than did kitchen area measurements (bias: $-89 \mu \mathrm{g} / \mathrm{m}^{3}$ ). Our findings demonstrate that indirect exposure reconstruction is a feasible approach to estimate personal exposure when direct assessment is not possible.
\end{abstract}

Keywords Household air pollution • Microenvironment $\cdot$ Fine particulate matters $\left(\mathrm{PM}_{2.5}\right) \cdot \mathrm{LPG}$ Intervention $\cdot$ Indirect exposure

\section{Introduction}

Approximately 3 billion people rely on solid fuels for cooking and heating globally due to lack of access to cleaner fuels [1]. According to the Global Burden of

Supplementary information The online version of this article (https:// doi.org/10.1038/s41370-019-0172-z) contains supplementary material, which is available to authorized users.

\section{Jiawen Liao}

Jiawen.liao@emory.edu

1 Department of Environmental Health, Emory University, Atlanta, GA, USA

2 Centro de Estudios en Salud, Universidad del Valle de Guatemala, Guatemala City, Guatemala

3 Berkeley Air Monitoring Group, Berkeley, CA, USA

4 Nell Hodgson Woodruff School of Nursing, Emory University, Atlanta, GA, USA
Disease, household air pollution (HAP) generated from cooking and heating with biomass stoves is associated with over 1.6 million premature deaths every year, mainly in low- and middle-income countries (LMICs) [2]. Young children and pregnant women are especially at risk from harmful exposure to HAP, since they spend the majority of their time indoors. HAP is associated with childhood acute lower respiratory infections $[3,4]$ and low birth weight $[5,6]$, both of which are the leading causes of death among

5 Department of Environmental and Radiological Health Sciences, Colorado State University, Fort Collins, CO, USA

6 Environmental Health Sciences, School of Public Health, University of California, Berkeley, CA, USA

7 College of Public Health, University of Georgia, Athens, GA, USA

8 Division of Pulmonary and Critical Care, School of Medicine, Johns Hopkins University, Baltimore, MD, USA

9 Center for Global Non-Communicable Diseases, Johns Hopkins University, Baltimore, MD, USA 
children under 5 year old in LMICs [7, 8]. However, HAP mitigation through cleaner cooking interventions, such as improved biomass stoves, has resulted in inconsistent results $[9,10]$, and many interventions have failed to sufficiently reduce HAP exposures.

Accurately assessing exposure to $\mathrm{HAP}$ - and thus the effectiveness of interventions to mitigate exposure-is challenging. Personal exposure monitors can be used on adults and older children to measure $\mathrm{PM}_{2.5}$ both gravimetrically and nephelometrically (continuously). Even the newer and more compact devices, such as the Enhanced Children's MicroPEM (ECM), which weighs $\sim 140 \mathrm{~g}$, with similar dimensions to a smart phone, are too heavy and large to be worn by children under 12 months for periods of $24 \mathrm{~h}$ [11]. When directly estimating personal exposure to $\mathrm{PM}_{2.5}$ is not feasible, some studies measure personal exposure to carbon monoxide (CO) with small, lightweight monitors easily worn by infants as a proxy of $\mathrm{PM}_{2.5}$ and HAP exposure [3, 12]. However, a systematic review of 61 studies from 27 countries has shown that $\mathrm{CO}$ is not always a consistently valid surrogate measurement for $\mathrm{PM}_{2.5}$ exposure [13]. Furthermore, the $\mathrm{PM}_{2.5}$ $\mathrm{CO}$ relationship may not be transportable across different study settings due to heterogeneous stove and fuel types, combustion conditions, and differences in other energy and housing-related factors. A second approach is to rely on measured kitchen area $\mathrm{PM}_{2.5}$ concentrations as a proxy for child exposure [14]. However, this method does not incorporate exposures during time spent away from the kitchen [15]. Another approach is to conduct an indirect or microenvironmental exposure assessment, which combines conventional pollutant measurements in various microenvironments with a time-activity diary or an objective measure of the location of participants in those microenvironments [16-19]. However, many of these studies assessed time-location patterns or microenvironmental locations using questionnaires or self-reported diaries, which are prone to recall bias and may not be accurate [20]. The use of questionnaires and self-reported diaries can be even more biased when mothers are asked to recall the time-location patterns of their children.

To improve the accuracy of $\mathrm{PM}_{2.5}$ exposure measurement, especially in children for whom it may be unfeasible to conduct direct measurements, there is a need for more precise, objective and less intrusive indirect $\mathrm{PM}_{2.5}$ monitoring methods [21]. Recently, a Bluetooth ${ }^{\circledR}$ Low Energy (BLE) Beacon proximity sensing system, which consists of signal loggers (sensors) and coin-sized signal emitters, was adapted to assess the indoor location of children during monitoring [22]. The application and accuracy of this Beacon system in indirect $\mathrm{PM}_{2.5}$ exposure assessment has not been evaluated in field HAP studies. Here, we report on formative research to evaluate an indirect $\mathrm{PM}_{2.5}$ exposure assessment method using the Beacon system with participants including women and children enrolled in the Household Air Pollution Intervention Network (HAPIN) trial in rural Guatemala.

\section{Methods}

\section{Purpose and design}

This study was conducted as one part of the formative research phase of the HAPIN trial in one of its intervention research centers in Jalapa, Guatemala [23]. This study was designed as a small LPG cookstove intervention, including a 2-month baseline period followed up with a 2-month LPG fuel and cookstove intervention period. During the 4-month study period, we conducted monthly visits to each household. This study was approved by the institutional review boards of the Universidad del Valle de Guatemala (146-08-2016/112016) and Emory University (00089799). The trial is registered at ClinicalTrials.gov (Identifier NCT02944682).

\section{Study sites and populations}

This study took place between November 2017 and April 2018, in Xalapán area of the Jalapa Department in rural Guatemala, $150 \mathrm{~km}$ east of Guatemala City. At an average elevation of 1500 meters, Xalapán has a tropical wet climate with an average temperature of $20^{\circ} \mathrm{C}$. This pilot study was conducted during the dry season with less than $50 \mathrm{~mm}$ rainfall per month. We recruited 20 households (1) that relied on woodstoves or open fires for cooking, (2) where a nonsmoking woman over the age of 35 years identified as the primary cook, and (3) who had a child aged $<1$ year. The selection criteria of households is based on the need for testing standardized operating procedures for the main HAPIN trial. Written informed consent was obtained from all participants.

\section{$\mathrm{PM}_{2.5}$ measurements}

For each household, we conducted four HAP assessments, two before and two after the LPG fuel intervention, for a total of 80 assessments. At each assessment, we measured 24-h microenvironmental area concentrations (in kitchens, sleeping area, and outdoor patios) and personal $\mathrm{PM}_{2.5}$ exposures using the ECM (RTI International, Durham, NC USA), the same device selected for exposure monitoring in the larger HAPIN main trial [24]. In kitchen and sleeping area microenvironments, ECMs, and personal locating Beacon loggers (more details in section 2.4.1) were placed $1.5 \mathrm{~m}$ above the floor, usually hanging on the wall, $1 \mathrm{~m}$ away from the edge of the combustion source and at least $1 \mathrm{~m}$ away from windows or doors. In the outdoor patio microenvironment, ECMs and Beacon loggers were placed 
in a secure area $1-2 \mathrm{~m}$ above the ground, usually installed under the outside edge of roof, at least $3 \mathrm{~m}$ away from the kitchen and other rooms. Instruments installed in one microenvironment were not visible from the other microenvironment.

ECMs were programmed to sample $\mathrm{PM}_{2.5}$ continuously using a nephelometer at a logging rate of $30 \mathrm{~s}$ and also collected gravimetric $\mathrm{PM}_{2.5}$ samples on a $15 \mathrm{~mm}$ Teflon filter (PT15-AN-PF02, MTL LLC., Minneapolis, MN, USA) at a flow rate of $0.3 \mathrm{~L} / \mathrm{min}$. Gravimetric $\mathrm{PM}_{2.5}$ measurements made with the ECM have a limit of detection of $5 \mu \mathrm{g} / \mathrm{m}^{3}$ for $24-\mathrm{h}$ sampling periods. All Teflon filters were pre and postweighed in a temperature- and humiditycontrolled laboratory at the University of Georgia with temperatures between 20 and $24^{\circ} \mathrm{C}$ and relative humidity between 30 and $40 \%$. Filters were stored in a $-20^{\circ} \mathrm{C}$ freezer after sampling in a laboratory at Universidad del Valle de Guatemala, and were transported in double ziplock bags in coolers with blue ice to the weighing laboratory. We collected 51 duplicate ECM samples (24-h sideby-side ECM measurements) and 34 field blank filters. In Fig. 1S, we showed that duplicate ECM samples had good agreement $\left(R^{2}=0.90\right)$. For all 34 field blanks, net weight changes were less than $5 \mu \mathrm{g}$, with a mean of 0.7 (SD: 2) $\mu \mathrm{g}$.

We calibrated all nephelometric continuous $\mathrm{PM}_{2.5}$ concentrations with the run-specific 24-h filter-based $\mathrm{PM}_{2.5}$ measurement. First, we calculated a calibration factor for each ECM deployment as the ratio between the 24-h filterbased gravimetric $\mathrm{PM}_{2.5}$ concentration and the corresponding 24-h average nephelometric $\mathrm{PM}_{2.5}$ concentration. Then, we multiplied each continuous nephelometric measurement by the calibration factor for each corresponding run to get the gravimetrically-adjusted nephelometric measurements. Finally, we averaged gravimetrically adjusted nephelometric measurements into 5-min intervals to reduce variability of the original 30 -s measurements. We used the gravimetrically adjusted continuous nephelometric $\mathrm{PM}_{2.5}$ concentrations to reconstruct $\mathrm{PM}_{2.5}$ exposures in this study.

\section{Microenvironment indirect $\mathrm{PM}_{2.5}$ exposure measurement methods}

\section{Beacon systems}

Beacon systems, consisting of personal Beacon emitters (Model O, Roximity Inc., Denver, CO, USA) and Beacon loggers (Berkeley Air Monitoring Group, Berkeley, CA, USA), were used to identify the microenvironments participants (women and children) moved through over time. The Beacon emitter (hereafter referred to as Beacon) is a coin size device that constantly emits Bluetooth signal, with battery life over 15 months. Women and children wore two Beacons each on their sampling vest (women) or clothing (infants) during each measurement (Fig. 1e). In each microenvironment, we concurrently deployed a fixedposition Beacon logger with ECMs. The Beacon logger is of similar size to a smart phone and is powered by a separate battery pack. Beacon loggers receive and log Bluetooth signals emitted from Beacons; they record the Beacon's unique Media access control address and the received signal strength indicator (RSSI) of Beacons every $20 \mathrm{~s}$ onto a microSD card. The RSSI is proportional to the distance between the Beacon and the Beacon logger, and thus can be used to determine the participants' microenvironmental locations. We classified participants' location in 5-minute intervals as the microenvironment where the Beacon logger recorded the strongest average RSSI from the two Beacons worn by participants. We assessed data quality of the Beacon system by checking whether Beacon loggers successfully logged data for $23-25$ h over the 24-h period, and whether data were logged in 20-s intervals. We only included data from the Beacon system for indirect $\mathrm{PM}_{2.5}$ exposure assessment if data passed quality checks without demonstrating the above problems.

\section{Walk-through test for Beacon systems}

At the beginning of each deployment, we carried out a 6-15-min-long walk-through procedure to assess the accuracy of the Beacon system's location prediction. During the walk-through procedure, field workers wore sampling vests containing all Beacons and walked through each microenvironment for 2-5 min, where Beacon loggers were installed. The start and end times in each microenvironment were recorded and regarded as the 'gold standard' of microenvironmental location classification during the walkthrough procedure. We defined the accurate prediction rate of microenvironmental location during the walk-through as the percentage of time when field workers are classified in the same microenvironment as recorded manually. In Fig. 2S, we show that the correct microenvironmental classification rate increases over time. During initial deployments of the system, due to suboptimal placement and system failures of Beacon loggers, the correct prediction rate of microenvironment was $40-50 \%$. At the end of this pilot study, after replacing malfunctioning Beacon loggers, correcting the set-up process, and optimizing Beacon logger placement in the outdoor patio area, the Beacon system was able to classify the microenvironment correctly at an average rate over $85 \%$ during walk-throughs.

\section{Indirect PM2.5 exposure estimation}

Equation 1 defines the indirect exposure (IE) estimate. IE is the time-weighted average of $\mathrm{PM}_{2.5}$ concentrations in microenvironments where participants spend time as 
Fig. 1 Setup of Beacon systems in the sleeping area (a), the kitchen (b), on the patio (d) and on a female participant (c). The dotted red circle in each panel highlights the sampling equipment and Beacon loggers. Panel (e) is a schematic sketch of the Beacon system and ECM setup

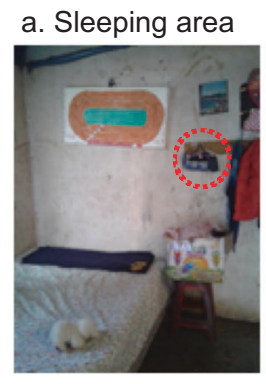

\section{b. Kitchen}

c. Mother's personal

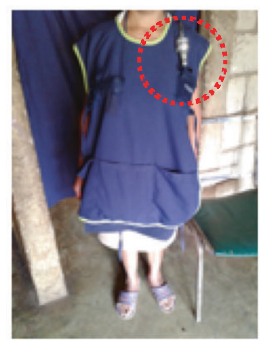

d. Outdoor patio

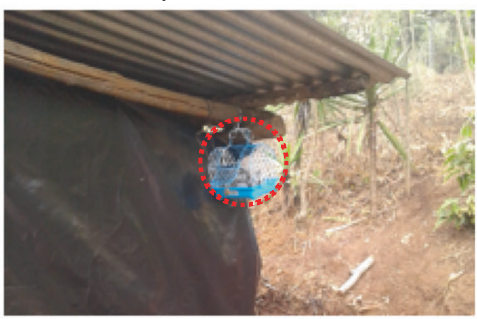

Beacon Logger

ECM

- Beacon Signal

Emitters

e. Diagram of Beacon Indirect Method Setup

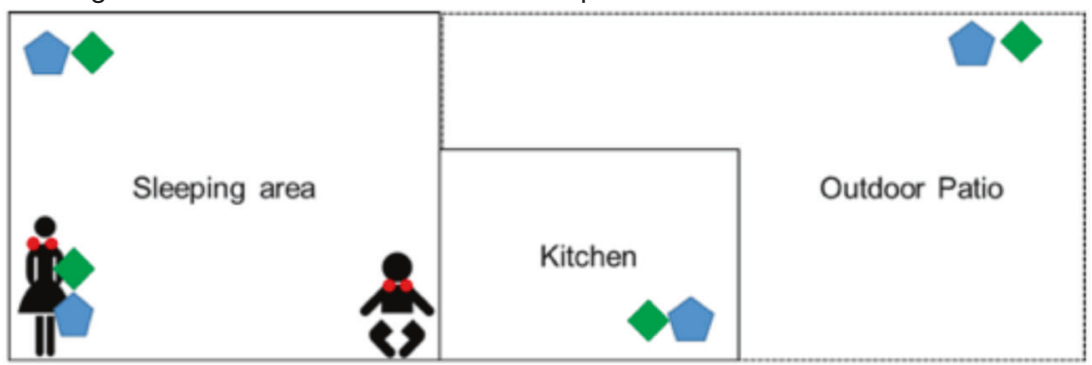

classified by the Beacon systems.

$\mathrm{IE}=\frac{\sum_{t} \sum_{m}\left(C_{t, m} L_{t, m} \Delta T\right)}{\sum_{t} \sum_{m}\left(L_{t, m} \Delta T\right)}=\sum_{m} \mathrm{IE}_{\mathrm{m}}$

IE refers to the total time-weighted average indirect exposure assessment, $\mathrm{IE}_{m}$ refers to the contribution of $\mathrm{PM}_{2.5}$ exposure in each microenvironment $m$ to the total time-weighted average indirect exposure. $C_{t, m}$ is the gravimetrically corrected nephelometric $\mathrm{PM}_{2.5}$ concentrations logged by an ECM at time $t$ in microenvironment $m$. $L_{t, m}$ is the indicator of the participant's location by the Beacon systems at time $t$, in microenvironment $m$. Specifically, $L_{t, m}=1$ if the participant is classified in microenvironment $m$ at time $t$, otherwise $L_{t, m}=0$. Notably, if none of Beacon loggers received Bluetooth signals from Beacons, we classify participants as outside of households, and will not have indirect $\mathrm{PM}_{2.5}$ measurements during that period of time. $\Delta T$ refers to the sampling interval, in this case $5 \mathrm{~min}$. In Fig. 3S, we show an example of a timeseries plot of RSSI and microenvironmental location classification for one measurement. In Fig. 4S, we show a time-series plot of indirect exposure and direct personal exposure from the same participant during the same measurement period.

\section{Indirect $\mathrm{PM}_{2.5}$ exposure for women}

In each household, the primary women cook wore two Beacons on their sampling vests along with a personal ECM to measure their direct personal exposure. Beacon loggers were placed together with ECMs in three microenvironments: kitchen, sleeping area, and outdoor patio. Women's indirect exposure is estimated using gravimetrically corrected nephelometric $\mathrm{PM}_{2.5}$ concentrations from the three fixed microenvironments, when women are classified in the given microenvironment by Beacon systems (Fig. 1a, b, d). Sixty-two (77\%) of 80 indirect exposure assessments were valid for women; 18 (23\%) measurements were removed due to low quality of data from Beacon loggers and (19\%) and system failures of ECMs (4\%). The low quality of Beacon logger data is mainly due to Beacon logger set up failures or obstruction of the Beacon signal. Therefore, for some Beacon loggers, we have no Beacon signal received and logged, and we will not have information of participants' proximity to corresponding microenvironments. 
Table 1 Area 24-h $\mathrm{PM}_{2.5}$ concentration, mean (SD), median (IQR), unit: $\mu \mathrm{g} / \mathrm{m}^{3}$

\begin{tabular}{lccccc}
\hline & Baseline & & & Follow-up & \\
\cline { 2 - 3 } \cline { 5 - 6 } & Mean (SD) & Median (IQR) & & Mean (SD) & Median (IQR) \\
\hline Kitchen & $397(301)$ & $308(227)$ & & $21(14)$ & $17(22)$ \\
Sleeping area & $113(172)$ & $34(101)$ & & $23(13)$ & $40(37)$ \\
Outdoor patio & $58(78)$ & $34(32)$ & & $22(18)$ & $20(24)$ \\
\hline
\end{tabular}

\section{Indirect $\mathrm{PM}_{2.5}$ exposure for children}

In each household, we deployed two Beacons on the clothing of each child under 1 year of age and assessed their microenvironmental locations. Children's indirect $\mathrm{PM}_{2.5}$ exposure is estimated using the gravimetrically corrected nephelometric $\mathrm{PM}_{2.5}$ concentrations from the three fixed microenvironment locations (kitchen, sleeping area, and outdoor patio) and the women's personal microenvironment, who also wore a Beacon logger (Fig. 1a-d). The purpose of adding one mobile microenvironment (that of the mother/women) is to ascertain the child's exposure when the child is next to the mother and potentially outside of the kitchen or sleeping area. However, if they are very close, even in kitchen or sleeping area, we also classified children to women's mobile microenvironment. Sixty-one (76\%) of 80 indirect exposure assessments were valid for children; 18 (24\%) measurements were removed due to low quality of Beacon logger data (19\%) or system failures of ECMs (5\%).

\section{Statistical methods}

Descriptive statistics, including the arithmetic mean, standard deviation (SD), median, and interquartile range (IQR) for 24-h $\mathrm{PM}_{2.5}$ concentrations from area and women's direct (personal) exposure samples were calculated. We reported both mean (SD) and median (IQR) statistics because 24-h $\mathrm{PM}_{2.5}$ concentrations and exposures are not normally distributed (right-skewed). Second, descriptive statistics (mean and SD) for women's and children's time spent in each microenvironment predicted by the Beacon system were calculated. We estimated women and children's indirect $\mathrm{PM}_{2.5}$ exposure and calculated descriptive statistics and estimated the mean contribution to indirect $\mathrm{PM}_{2.5}$ exposure from each microenvironment. To evaluate the performance of the Beacon-derived indirect exposure methods, we compared women's direct (personal) exposure measurements with indirect measurements and calculated Spearman correlation coefficients. We created Bland-Altman plots to evaluate agreement between direct personal exposure, indirect exposure, and kitchen measurements. We calculated the root mean squared error (RMSE) of indirect exposure estimates and kitchen area $\mathrm{PM}_{2.5}$ concentrations compared to direct personal exposure measurements, respectively. Bias was calculated separately as the mean difference of direct personal and indirect measures and the mean difference of the direct personal and kitchen paired $\mathrm{PM}_{2.5}$ concentrations, respectively. Data analysis was conducted in $\mathrm{R}$ (version 3.5.0, the $\mathrm{R}$ foundation, Vienna, Austria) and used the ggplot 2 package for generating figures.

\section{Results}

\section{Household characteristics and area $\mathbf{P M}_{2.5}$ concentrations}

Among 20 household in this study, most $(n=17,85 \%)$ had a fully enclosed kitchen with a roof and four walls. The walls of households were made of bricks and roofs were made of wood or corrugated metal. The average size of an enclosed kitchen was $14.2 \mathrm{~m}^{2}$, with an average of height of $2.5 \mathrm{~m}$. The kitchens were potentially well ventilated in the households, with an average of 11 windows or apertures. Table 1 shows 24-h area $\mathrm{PM}_{2.5}$ concentrations during the pre-LPG baseline measurements and the post-LPG followup period. We observed high 24-h area $\mathrm{PM}_{2.5}$ concentrations during baseline measures compared to the follow-up period. We found $94 \%, 79 \%$, and $62 \%$ reductions in $24-\mathrm{h}$ $\mathrm{PM}_{2.5}$ levels in the kitchen, sleeping area, and outdoor patio area microenvironments.

\section{Indirect exposure assessment}

\section{Time spent in each microenvironment for women and Children}

Figure 2 shows the average estimated hours (over a 24-h period) that women and children spent in each microenvironment, as well as time outside of the household in the pre- and post-LPG intervention periods. Women spent $12.8 \mathrm{~h}$ in the sleeping area, $6.2 \mathrm{~h}$ in kitchen and $3.5 \mathrm{~h}$ in the outdoor patio. Children spent $11.3 \mathrm{~h}$ with their mothers, $8.2 \mathrm{~h}$ in bedroom and $2 \mathrm{~h}$ in the outdoor patio microenvironment. Women and children spent $0.9 \mathrm{~h}$ outside of the monitored household microenvironments on average. We found that the LPG intervention was not associated with women's time in any of the three microenvironments and 
was only statistically significantly associated with children's time in the sleeping area (Two-sided $t$-test $p=0.01$ ).

\section{Indirect $\mathrm{PM}_{2.5}$ exposure for women}

Women participants reported high compliance of wearing sampling vest. The average time not wearing sampling equipment aside from sleeping and bathing was $1.1 \mathrm{~h}$. Table 2 lists the mean and median 24-h women's direct exposures and indirect $\mathrm{PM}_{2.5}$ exposure reconstructions in pre- and post-LPG periods, along with Spearman correlation coefficients between the indirect and direct measurements. The means of direct and indirect $\mathrm{PM}_{2.5}$ exposure are 189 (SD: 138) $\mu \mathrm{g} / \mathrm{m}^{3}$, and 258 (SD: 194) $\mu \mathrm{g} / \mathrm{m}^{3}$, respectively, both of which are well above World Health Organization (WHO) Interim Target 1 guideline of $35 \mu \mathrm{g} / \mathrm{m}^{3}$. We found a 75 and $91 \%$ reduction in direct and indirect $24-\mathrm{h}$ mean $\mathrm{PM}_{2.5}$ exposures after LPG intervention, respectively.

Indirect measures of $\mathrm{PM}_{2.5}$ are highly correlated with direct personal measures for women, with a Spearman correlation of
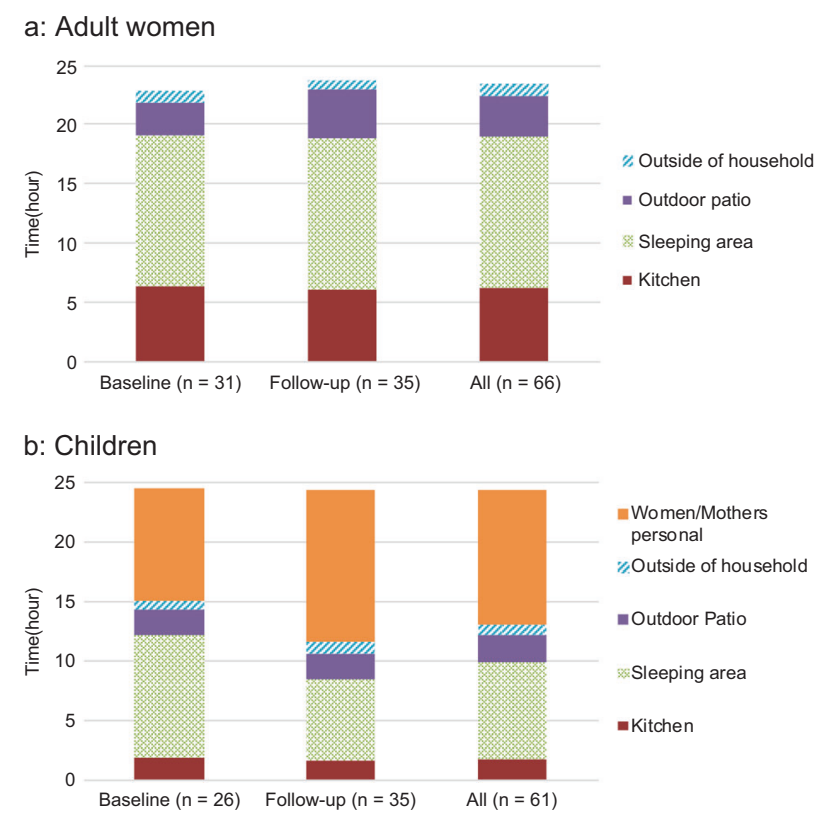

Fig. 2 Daily average time (hour) spent in each microenvironment for women (a) and children (b)
0.81 (Fig. 5S). Figure 3 shows the mean of women's direct $\mathrm{PM}_{2.5}$ exposure and indirect $\mathrm{PM}_{2.5}$ exposure and the contribution of each microenvironmental $\mathrm{PM}_{2.5}$ measurement to the indirect $\mathrm{PM}_{2.5}$ exposure estimates. In the baseline period, indirect exposure estimates were higher than the direct exposure measurements, and $\mathrm{PM}_{2.5}$ exposures from the kitchen microenvironment contributed most strongly to the average indirect exposure. In the post-LPG period, direct exposures were higher than indirect exposures and the sleeping area contributed most of indirect exposure for women.

Figure 4 shows the Bland-Altman plot of 24-h direct versus indirect $\mathrm{PM}_{2.5}$ measurements (left panel) and direct versus kitchen $\mathrm{PM}_{2.5}$ measurement (right panel) for women. The $x$-axis of the plot is the average of two measurements, and the $y$-axis is the 24-h direct measurement minus indirect measurement (left panel) or 24-h direct measurement minus kitchen measurement (right panel), respectively. The blue line is the mean of the measurement differences ( $y$-axis value) and two red lines are $95 \%$ confidence interval of the measurement differences. The left panel (a) of Fig. 3 shows a smaller difference between two measurements and dots are less deviated from the blue centerline, compared to the right panel (b). Indirect measurements have less bias and have better agreement with direct personal measurement when compared with kitchen measurements (Fig. 4). Table 3 shows the RMSE and bias of direct-indirect $\mathrm{PM}_{2.5}$ exposure pairs and direct-kitchen $\mathrm{PM}_{2.5}$ concentration pairs by LPG intervention period. When compared to women's direct $\mathrm{PM}_{2.5}$ exposure, the RMSE of the women's indirect $\mathrm{PM}_{2.5}$ exposure was $128 \mu \mathrm{g} / \mathrm{m}^{3}$ and the RMSE of kitchen $\mathrm{PM}_{2.5}$ concentration was $250 \mu \mathrm{g} / \mathrm{m}^{3}$. The average bias between direct-indirect $\mathrm{PM}_{2.5}$ exposure was $-17 \mu \mathrm{g} / \mathrm{m}^{3}$ (indicating overestimation of the indirect method), and average bias between direct-kitchen $\mathrm{PM}_{2.5}$ was $-89 \mu \mathrm{g} /$ $\mathrm{m}^{3}$. Most of the error and bias come from the pre-LPG intervention baseline phase, as indirect exposure and kitchen area measurement overestimated direct personal $\mathrm{PM}_{2.5}$ exposure levels (Table 3).

\section{Indirect $\mathrm{PM}_{2.5}$ exposure prediction for children}

Children shown high compliance of wearing Beacons. Women participants reported their children not wore
Table 2 Direct and indirect $\mathrm{PM}_{2.5}$ exposure for women, unit: $\mu \mathrm{g} / \mathrm{m}^{3}$

\begin{tabular}{llll}
\hline & $\begin{array}{l}\text { Baseline } \\
n=27\end{array}$ & $\begin{array}{l}\text { Follow-up } \\
n=35\end{array}$ & $\begin{array}{l}\text { Overall } \\
n=62\end{array}$ \\
\hline Direct personal $\mathrm{PM}_{2.5}$ exposure & $189(138)$, & $47(29)$, & $109(116)$, \\
$\quad$ Mean(SD), median (IQR) & $119(164)$ & $42(31)$ & $66(79)$ \\
$\quad$ Indirect PM ${ }_{2.5}$ exposure & $258(194)$, & $23(13)$, & $125(172)$, \\
$\quad$ Mean(SD),median (IQR) & $188(214)$ & $21(21)$ & $39(135)$ \\
Spearman correlation coefficient between women's & 0.63 & 0.66 & 0.81 \\
direct and indirect $\mathrm{PM}_{2.5}$ measure & & & \\
\hline
\end{tabular}

$S D$ standard deviation, $I Q R$ interquartile range 
Beacon only for average $0.2 \mathrm{~h}$ among 80 measurements, aside from sleeping and bathing. Table 4 lists the mean (SD) and median (IQR) of indirect $\mathrm{PM}_{2.5}$ exposures for children by intervention period. We found that children's indirect $\mathrm{PM}_{2.5}$ exposure was reduced by $77 \%$, from a mean of 175 (SD, 123) $\mu \mathrm{g} / \mathrm{m}^{3}$ to 39 (SD, 26) $\mu \mathrm{g} / \mathrm{m}^{3}$ after LPG intervention. In Fig. 5, we show the mean of children's indirect $\mathrm{PM}_{2.5}$ exposure and the contribution of each microenvironment to indirect $\mathrm{PM}_{2.5}$ exposure. In the pre-LPG period, the women/mothers' personal 'microenvironment' contributed most strongly, followed by $\mathrm{PM}_{2.5}$ in the kitchen microenvironment. In the post-LPG period, women/ mother's personal microenvironment contributed most to the indirect $\mathrm{PM}_{2.5}$ exposure.

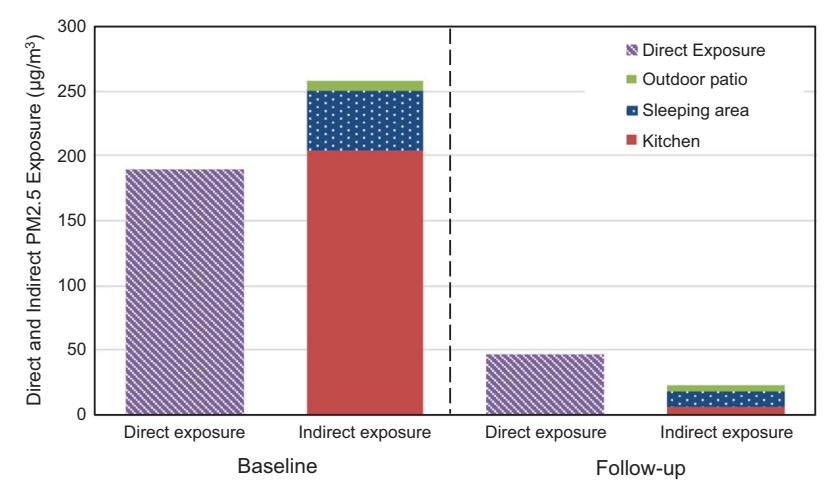

Fig. 3 Direct and indirect $\mathrm{PM}_{2.5}$ exposures for women and the contribution of indirect exposure from each microenvironment (kitchen, sleeping area, and outdoor patio)

\section{Discussion}

In this study, we demonstrated the feasibility of objectively monitoring the location of participants including adult women and children in their homes using a BLE Beacon proximity sensing system. This system, when combined with ECM $\mathrm{PM}_{2.5}$ monitors placed in microenvironments throughout the home, enabled reconstructions of personal exposures that were highly correlated with direct measurements of $\mathrm{PM}_{2.5}$ exposure. The same system enabled accurate prediction of the location of children under 1 year of age and enabled reconstructions of their exposure to $\mathrm{PM}_{2.5}$ over $24 \mathrm{~h}$ periods.

To our knowledge, this is the first study evaluating indirect exposure to $\mathrm{PM}_{2.5}$ using personal locating technology and microenvironment $\mathrm{PM}_{2.5}$ monitors in HAP field studies. Previous studies mainly applied time-activity questionnaires or diaries as self-reported records of microenvironmental location [11, 16-19]. A few studies have applied an objective personal locator for timelocation assessment in similar settings in Guatemala; those studies relied on an ultrasound emitter and detector to provide a binary presence or absence in a specific microenvironment $[25,26]$. Most of the previous studies using indirect exposure approaches did not validate the accuracy of the time-location patterns reported by participants. We conducted walk-through tests by comparing records from field workers (our gold standard) with locations determined by the Beacon logger, and found Beacon systems could accurately predict location $89 \%$ of the time on average. This finding of high microenvironment predicting accuracy of the Beacon system is

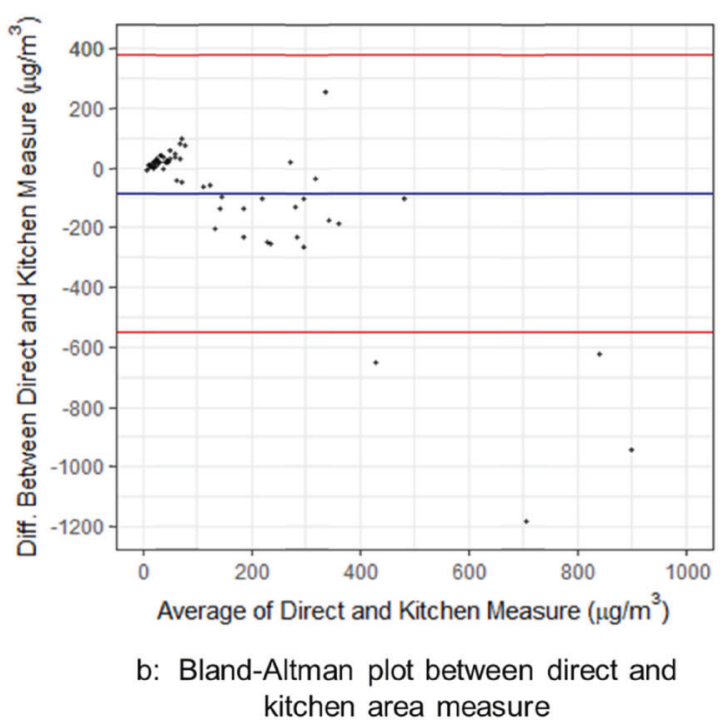

Fig. 4 Bland-Altman plot of women's 24-h direct and indirect (a) and women's direct and kitchen area $\mathrm{PM}_{2.5}$ measure (b) 
Table 3 RMSE and bias between direct-indirect and direct-kitchen paired $\mathrm{PM}_{2.5}$, unit: $\mu \mathrm{g} / \mathrm{m}^{3}$

\begin{tabular}{lllll}
\hline \multirow{2}{*}{ RMSE } & & $\begin{array}{l}\text { Baseline } \\
n=27\end{array}$ & $\begin{array}{l}\text { Follow-up } \\
n=35\end{array}$ & $\begin{array}{l}\text { Overall } \\
n=62\end{array}$ \\
\cline { 3 - 5 } \multirow{3}{*}{ Bias } & Direct-indirect & 189 & 34 & 128 \\
& Direct-kitchen & 377 & 35 & 250 \\
& Direct-indirect & -70 & 24 & -17 \\
& Direct-kitchen & -230 & 26 & -89 \\
\hline
\end{tabular}

$R M S E$ root mean squared error

Table 4 Children's indirect $\mathrm{PM}_{2.5}$ exposure

\begin{tabular}{llll}
\hline $\begin{array}{l}\text { Indirect } \mathrm{PM}_{2.5} \\
\text { exposure estimate }\end{array}$ & $\begin{array}{l}\text { Baseline } \\
n=26\end{array}$ & $\begin{array}{l}\text { Follow-up } \\
n=35\end{array}$ & $\begin{array}{l}\text { Overall } \\
n=61\end{array}$ \\
\hline Mean (SD) & $175(125)$ & $39(26)$ & $97(107)$ \\
Median (IQR) & $141(160)$ & $35(30)$ & $51(90)$ \\
\hline
\end{tabular}

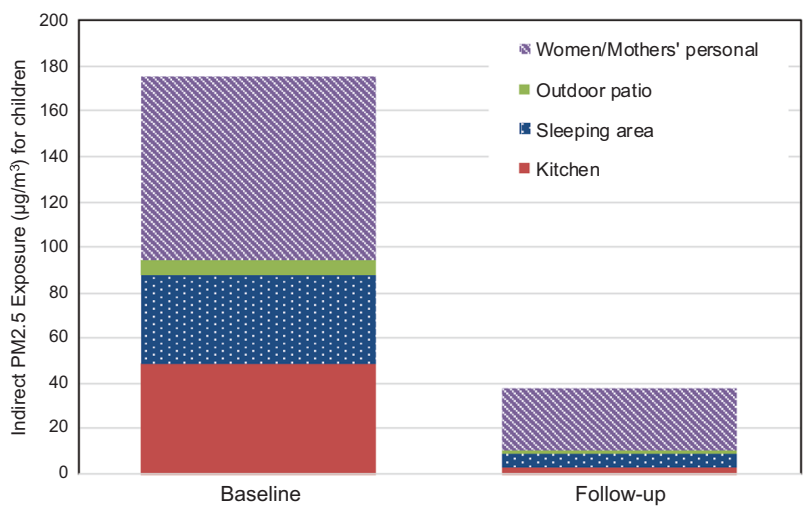

Fig. 5 Indirect $\mathrm{PM}_{2.5}$ exposure for children and contribution of indirect exposure from microenvironment locations (kitchen, sleeping area, outdoor patio, and women/mothers' personal direct microenvironment)

consistent with a previous study that utilized ultrasound personal locator devices [25].

For adult women, the Beacon system indicated that they spent half of their time in sleeping area $(12.8 \mathrm{~h}$ per day), followed by kitchen ( $6.2 \mathrm{~h}$ per day) and outdoor patio ( $3.5 \mathrm{~h}$ per day) microenvironments, and $0.9 \mathrm{~h}$ out of any of these microenvironments. These findings are similar to studies conducted in India [17, 19], Kenya [16], and Mexico [18], all of which found women cooks spend around $12 \mathrm{~h}$ per day in the living room or sleeping room, followed by $4-7 \mathrm{~h}$ per day in the kitchen. Notably, we found that time-activity patterns did not seem to change between pre- and post-LPG periods for women. This is consistent with the findings of Zuk et al. [18], who did not find a change in time-activity patterns from an improved biomass stove intervention in rural Mexico. For children under 1 year old, we found that they spent most of the time with mothers or in the sleeping area. Notably, we classified children into women/mothers' microenvironment if they were close together, even if they are in the kitchen or sleeping areas. Our findings are consistent with findings from older children in Nepal [11] and Kenya [16], where children spent $12.2 \mathrm{~h}$ per day and $44 \%$ of their time in the living room or sleeping area, respectively. Interestingly, we found that the LPG fuel intervention increased the time children spent with their mothers $(3.3 \mathrm{~h})$. However, since our study did not collect selfreported time-activity diaries from participants and due to a relatively limited number of samples, more studies are needed to confirm the effect of LPG interventions on timeactivity patterns. In addition, we found that women were not in any of the measured microenvironments for, on average, $1 \mathrm{~h}$ per day. During these periods, no indirect measurement of exposure to $\mathrm{PM}_{2.5}$ was captured. This is possibly due to some participants leaving their households during the day to visit friends or relatives, or to go shopping, and also due to a few participants who went to another home to sleep at night. We still included these households in our evaluation of indirect exposure assessment of the women, because we believe these indirect exposure measurements, even lacking a few hours of data, are still useful for predicting daily exposure levels. Sensitivity analysis excluding measurements with more than $4 \mathrm{~h}$ outside of households $(n=3)$ shown that the time spent and indirect exposure changed less than $10 \%$ compared to original results.

Our study illustrates that indirect $\mathrm{PM}_{2.5}$ exposure estimates derived from the Beacon system showed a stronger correlation with direct measurements of $\mathrm{PM}_{2.5}$ personal exposure $(\rho=0.81)$, than did correlations between kitchen microenvironment $\mathrm{PM}_{2.5}$ levels and direct personal measurements of $\mathrm{PM}_{2.5}$ exposure levels $(\rho=0.68)$. As shown in the Bland-Altman plot (Fig. 4), indirect exposure measurements tended to have less bias and agree better with direct personal exposure than kitchen area $\mathrm{PM}_{2.5}$ measurements. Therefore, the Beacon indirect exposure method described here better estimates exposures than does simply using area measurements as a proxy for exposure, a common, but perhaps inaccurate, method used to estimate $\mathrm{PM}_{2.5}$ exposures for infants [27, 28]. Our findings confirm other recent data from HAPIN formative research indicating that the LPG intervention can reduce $\mathrm{PM}_{2.5}$ levels close to the WHO target of $35 \mu \mathrm{g} / \mathrm{m}^{3}$. [29] Prior estimates of an LPG intervention effect were around $70 \mu \mathrm{g} / \mathrm{m}^{3}$. [30] Despite the fact that we provided a 3-month supply of free LPG gas cylinders, it is likely that some continued used of biomass fuel (stove stacking) and air pollution from neighboring households increased $\mathrm{PM}_{2.5}$ exposure above what we would have observed with only gas fuel use. 
The new indirect microenvironment exposure approach in our study has a number of advantages over typical indirect exposure assessment. First, we applied a Beacon proximity sensor system, an objective personal locating system to assess microenvironmental locations of participants. This approach can reduce error and recall bias from self-reported timeactivity data. Second, we used gravimetrically corrected continuous microenvironmental $\mathrm{PM}_{2.5}$ concentrations to reconstruct indirect exposures. Compared to other similar studies using time-activity patterns or microenvironmental approaches [11, 18], our study has the advantage to capture temporal variation and peaks of $\mathrm{PM}_{2.5}$ for indirect exposure.

We also found that indirect exposure estimation from the Beacon system has some limitations and biases. We expect two types of bias would emerge from indirect exposure assessment compared to direct personal exposure. One type of bias is that the indirect method is not able to capture all of the microenvironments participants move through and could mischaracterize locations of participants. Another type of bias emerges when area $\mathrm{PM}_{2.5}$ measures differed from true personal direct $\mathrm{PM}_{2.5}$ measures, which reflects differences between area ECM $\mathrm{PM}_{2.5}$ monitors and personal monitors when participants locations are known. Figure 4 illustrates heteroscedasticity using indirect exposure to predict indirect exposure, indicating error of indirect exposure increases as $\mathrm{PM}_{2.5}$ level increases. Table 4 shows that in the pre-LPG baseline period, indirect exposure overestimated direct exposure but in the post-LPG followup period, indirect exposure tended to underestimate direct exposure. The overestimation at baseline may be due to differences between personal monitors and area monitors in households cooking with biomass stoves/open fires, with area monitors being closer to the open fire. The underestimation of indirect exposures in post-LPG follow-up periods may be due to the existence of other sources of air pollution, which is captured by the personal monitor but not necessarily by area monitors, and may have a greater relative importance when kitchen measurements have been sharply lowered. We show in the supplementary materials that compared to personal direct exposure measurement (gold standard), the Beacon indirect method will likely over-estimate personal exposure levels in biomass households and likely underestimate personal exposure levels in LPG intervention households, which is in fact what we have observed.

It is also worth noting that we have relatively high failure rates for the Beacon system (19\%, 15 measurements out of 80 measurements), mainly due to incorrect set up of 10 (13\%) Beacon loggers leading to failures of Beacon logger systems, and $5(6 \%)$ Beacon logger misplacement in outdoor patio areas, leading to the obstruction of Beacon signals. However, we found these failures occurred mainly in the beginning phase of this study and could be largely prevented if additional training of field workers was conducted to ensure proper set up of Beacon loggers. Despite these limitations, our study still showed that the combination of the Beacon system and ECM monitors is a precise and feasible indirect method to assess exposure to $\mathrm{PM}_{2.5}$ in low-and-middle-income settings for children, especially when direct personal exposure measurement is not practical.

\section{Conclusion}

We assessed an indirect, sensor-enabled exposure measurement technique in households using woodstoves at baseline and an LPG cookstove at follow-up. This information adds evidence that indirect exposure assessment using the Beacon system as a microenvironmental location monitor provides an acceptable estimate of personal exposures in biomass and LPG stove settings. We found that indirect exposure methods have higher correlation with direct personal exposure measurements and less bias than do kitchen measurements. In settings where conducting personal direct exposure assessment is not practical, such as for children under 1 year old, the Beacon indirect exposure method is an alternative that provides better estimates of personal exposure to $\mathrm{PM}_{2.5}$. The results of this study can inform exposure assessments for future HAP studies.

Acknowledgements This study was supported through the National Heart, Lung, and Blood Institute/National Institutes of Health [1UM1HL134590-01] and Bill \& Melinda Gates Foundation [OPP1131279]. A multidisciplinary, independent Data and Safety Monitoring Board (DSMB) appointed by the National Heart, Lung, and Blood Institute (NHLBI) monitors the quality of the data and protects the safety of patients enrolled in the HAPIN trial. NHLBI DSMB: Nancy R. Cook, Sc.D.; Stephen Hecht, Ph.D.; Catherine Karr, M.D., Ph.D.; Katie H. Kavounis, M.P.H.; Dong-Yun Kim, Ph.D.; Joseph Millum, Ph.D.; Lora A. Reineck, M.D., M.S.; Nalini Sathiakumar, M.D., Dr.P.H.; Paul K. Whelton, M.D.; Gail G. Weinmann, M.D. Program Coordination: Gail Rodgers, M.D., Bill \& Melinda Gates Foundation; Claudia L. Thompson, Ph.D. National Institute of Environmental Health Science (NIEHS); Mark J. Parascandola, Ph.D., M.P.H., National Cancer Institute (NCI); Danuta M. Krotoski, Ph.D., Eunice Kennedy Shriver National Institute of Child Health and Human Development (NICHD); Joshua P. Rosenthal, Ph.D. Fogarty International Center (FIC), Conception R. Nierras, Ph.D. NIH Office of Strategic Coordination Common Fund; Antonello Punturieri, M.D., Ph.D. and Barry S. Schmetter, National Heart, Lung, and Blood Institute (NHLBI). The content is solely the responsibility of the authors and does not necessarily represent the official views of the National Institutes of Health or Bill \& Melinda Gates Foundation.

HAPIN investigators: Vigneswari Aravindalochanan ${ }^{10}$, Kalpana Balakrishnan $^{10}$, Dana Boyd Barr ${ }^{1}$, Vanessa Burrowes ${ }^{11}$, Devan Campbell $^{7}$, Julia McPeek Campbell ${ }^{1}$, Adly Castañaza ${ }^{2}$, Howard Chang $^{12}$, Yunyun Chen ${ }^{12}$, Marilú Chiang ${ }^{13}$, Rachel Craik ${ }^{14}$, Mary Crocker $^{15}$, Victor Davila-Roman ${ }^{16}$, Lisa de las Fuentes ${ }^{16}$, Ephrem Dusabimana $^{17}$, Lisa Elon ${ }^{12}$, Juan Gabriel Espinoza ${ }^{13}$, Irma Sayury Pineda Fuentes ${ }^{2}$, Sarada Garg ${ }^{10}$, Dina Goodman ${ }^{11}$, Savannah Gupton ${ }^{1}$, 
Stella Hartinger ${ }^{18}$, Steven Harvey ${ }^{19}$, Mayari Hengstermann ${ }^{20}$, Phabiola Herrera $^{21}$, Shakir Hossen ${ }^{11}$, Penelope Howards ${ }^{12}$, Lindsay Jaacks ${ }^{22}$, Shirin Jabbarzadeh ${ }^{12}$, Abigail Jones ${ }^{7}$, Miles Kirby ${ }^{1}$, Jacob Kremer ${ }^{7}$, Margaret Laws $^{11}$, Amy Lovvorn ${ }^{1}$, Fiona Majorin ${ }^{23}$, Eric McCollum ${ }^{11}$, Rachel Meyers ${ }^{16}$, J. Jaime Miranda ${ }^{24}$, Lawrence Moulton ${ }^{25}$, Krishnendu Mukhopadhyay ${ }^{10}$, Abidan Nambajimana ${ }^{17}$, Florien Ndagijimana $^{17}$, Azhar Nizam ${ }^{12}$, Jean de Dieu Ntivuguruzwa ${ }^{17}$, Aris Papageorghiou ${ }^{14}$, Naveen Puttaswamy ${ }^{10}$, Elisa Puzzolo ${ }^{26}$, Ashlinn Quinn $^{27}$, Sarah Rajkumar ${ }^{5}$, Usha Ramakrishnan ${ }^{12}$, Davis Reardon ${ }^{7}$, Ghislaine Rosa ${ }^{23}$, Joshua Rosenthal ${ }^{27}$, P. Barry Ryan ${ }^{1}$, Zoe Sakas ${ }^{23}$, Sankar Sambandam ${ }^{10}$, Jeremy Sarnat ${ }^{1}$, Suzanne Simkovich ${ }^{11}$, Sheela Sinharoy ${ }^{1}$, Kirk R. Smith ${ }^{6}$, Damien Swearing ${ }^{1}$, Gurusamy Thangavel $^{10}$, Ashley Toenjes ${ }^{16}$, Lindsay Underhill ${ }^{11}$, Jean Damascene Uwizeyimana $^{17}$, Viviane Valdes ${ }^{12}$, Amit Verma ${ }^{12}$, Lance Waller ${ }^{12}$, Megan Warnock $^{12}$, Kendra Williams ${ }^{11}$, Wenlu $\mathrm{Ye}^{1}$, Bonnie Young ${ }^{5}$

${ }^{10}$ Sri Ramachandra Institute of Higher Education and Research, Chennai, India; ${ }^{11}$ School of Medicine, Johns Hopkins University, Baltimore, MD, USA; ${ }^{12}$ Rollins School of Public Health, Emory University, Atlanta, GA, USA; ${ }^{13}$ A.B. PRISMA, San Miguel, Peru; ${ }^{14}$ University of Oxford, Oxford, UK; ${ }^{15}$ Seattle Children's Hospital, Seattle, USA; ${ }^{16}$ Washington University in St. Louis, St. Louis, MO, USA; ${ }^{17}$ Eagle Research Center, Kigali, Rwanda; ${ }^{18}$ Universidad Peruana Cayetano Heredia, Lima, Peru; ${ }^{19}$ Johns Hopkins Bloomburg School of Public Health, Johns Hopkins University, Baltimore, MD, USA; ${ }^{20}$ Freie Universitat Berlin, Berlin, Germany; ${ }^{21}$ Johns Hopkins University, Baltimore, MD, USA; ${ }^{22}$ T.H. Chan School of Public Health, Harvard University, Boston, MA, USA; ${ }^{23}$ London School of Hygiene and Tropical Medicine, London, UK; ${ }^{24}$ School of Medicine, Universidad Peruana Cayetano Heredia, Lima, Peru; ${ }^{25}$ Johns Hopkins Bloomberg School of Public Health, Johns Hopkins University, Baltimore, MD, USA; ${ }^{26}$ Global LPG Partnership, New York, NY, USA; ${ }^{27}$ Fogarty International Center, National Institutes of Health, Bethesda, MD, USA

\section{Compliance with ethical standards}

Conflict of interest The authors declare that they have no conflict of interest.

Publisher's note Springer Nature remains neutral with regard to jurisdictional claims in published maps and institutional affiliations.

Open Access This article is licensed under a Creative Commons Attribution 4.0 International License, which permits use, sharing, adaptation, distribution and reproduction in any medium or format, as long as you give appropriate credit to the original author(s) and the source, provide a link to the Creative Commons license, and indicate if changes were made. The images or other third party material in this article are included in the article's Creative Commons license, unless indicated otherwise in a credit line to the material. If material is not included in the article's Creative Commons license and your intended use is not permitted by statutory regulation or exceeds the permitted use, you will need to obtain permission directly from the copyright holder. To view a copy of this license, visit http://creativecommons. org/licenses/by/4.0/.

\section{References}

1. Bonjour S, Adair-Rohani H, Wolf J, Bruce NG, Mehta S, Prüss-Ustün A, et al. Solid fuel use for household cooking: country and regional estimates for 1980-2010. Environ Health Perspect. 2013;121:784-90.
2. Stanaway JD, Afshin A, Gakidou E, Lim SS, Abate D, Abate KH, et al. Global, regional, and national comparative risk assessment of 84 behavioural, environmental and occupational, and metabolic risks or clusters of risks for 195 countries and territories, 1990-2017: a systematic analysis for the Global Burden of Disease Study 2017. Lancet. 2018;392:1923-94.

3. Smith KR, McCracken JP, Weber MW, Hubbard A, Jenny A, Thompson LM, et al. Effect of reduction in household air pollution on childhood pneumonia in Guatemala (RESPIRE): a randomised controlled trial. Lancet. 2011;378:1717-26.

4. Gurley ES, Homaira N, Salje H, Ram PK, Haque R, Petri W, et al. Indoor exposure to particulate matter and the incidence of acute lower respiratory infections among children: a birth cohort study in urban Bangladesh. Indoor Air. 2013;23:379-86.

5. Pope DP, Mishra V, Thompson L, Siddiqui AR, Rehfuess EA, Weber M, et al. Risk of low birth weight and stillbirth associated with indoor air pollution from solid fuel use in developing countries. Epidemiol Rev. 2010;32:70-81.

6. Amegah AK, Quansah R, Jaakkola JJK. Household air pollution from solid fuel use and risk of adverse pregnancy outcomes: a systematic review and meta-analysis of the empirical evidence. PLOS ONE. 2014;9:e113920.

7. Naghavi M, Abajobir AA, Abbafati C, Abbas KM, Abd-Allah F, Abera SF, et al. Global, regional, and national age-sex specific mortality for 264 causes of death, 1980-2016: a systematic analysis for the Global Burden of Disease Study 2016. Lancet. 2017;390:1151-210.

8. Roth GA, Abate D, Abate KH, Abay SM, Abbafati C, Abbasi N, et al. Global, regional, and national age-sex-specific mortality for 282 causes of death in 195 countries and territories, 1980-2017: a systematic analysis for the Global Burden of Disease Study 2017. Lancet. 2018;392:1736-88.

9. Mortimer K, Ndamala CB, Naunje AW, Malava J, Katundu C, Weston $\mathrm{W}$, et al. A cleaner burning biomass-fuelled cookstove intervention to prevent pneumonia in children under 5 years old in rural Malawi (the Cooking and Pneumonia Study): a cluster randomised controlled trial. Lancet. 2017;389:167-75.

10. Thakur M, Nuyts PAW, Boudewijns EA, Kim JF, Faber T, Babu GR, et al. Impact of improved cookstoves on women's and child health in low and middle income countries: a systematic review and meta-analysis. Thorax. 2018;73:1026-40.

11. Devakumar D, Semple S, Osrin D, Yadav SK, Kurmi OP, Saville $\mathrm{NM}$, et al. Biomass fuel use and the exposure of children to particulate air pollution in southern Nepal. Environ Int. 2014;66:79-87.

12. Dionisio KL, Howie SRC, Dominici F, Fornace KM, Spengler JD, Donkor S, et al. The exposure of infants and children to carbon monoxide from biomass fuels in The Gambia: a measurement and modeling study. J Expo Sci Environ Epidemiol. 2012;22:173-81.

13. Carter E, Norris C, Dionisio KL, Balakrishnan K, Checkley W, Clark ML, et al. Assessing exposure to household air pollution: a systematic review and pooled analysis of carbon monoxide as a surrogate measure of particulate matter. Environ Health Perspect. 2017;125:076002.

14. Dionisio KL, Howie SRC, Dominici F, Fornace KM, Spengler JD, Adegbola RA, et al. Household concentrations and exposure of children to particulate matter from biomass fuels in the Gambia. Environ Sci Technol. 2012;46:3519-27.

15. World Health Organization. Indoor air pollution and household energy monitoring: workshop resources. Geneva: World Health Organization; 2005. http://www.who.int/iris/handle/10665/43371. Accessed 27 Jan 2018.

16. Ezzati M, Saleh H, Kammen DM. The contributions of emissions and spatial microenvironments to exposure to indoor air pollution from biomass combustion in Kenya. Environ Health Perspect. 2000;108:833-9. 
17. Balakrishnan K, Sankar S, Parikh J, Padmavathi R, Srividya K, Venugopal V, et al. Daily average exposures to respirable particulate matter from combustion of biomass fuels in rural households of southern India. Environ Health Perspect. 2002;110:1069-75.

18. Zuk M, Rojas L, Blanco S, Serrano P, Cruz J, Angeles F, et al. The impact of improved wood-burning stoves on fine particulate matter concentrations in rural Mexican homes. J Expo Sci Environ Epidemiol. 2007;17:224-32.

19. Sidhu MK, Ravindra K, Mor S, John S. Household air pollution from various types of rural kitchens and its exposure assessment. Sci Total Environ. 2017;586:419-29.

20. Daum T, Buchwald H, Gerlicher A, Birner R. Smartphone apps as a new method to collect data on smallholder farming systems in the digital age: a case study from Zambia. Computers Electron Agriculture. 2018;153:144-50.

21. Clark ML, Peel JL, Balakrishnan K, Breysse PN, Chillrud SN, Naeher LP, et al. Health and household air pollution from solid fuel use: the need for improved exposure assessment. Environ Health Perspect. 2013;121:1120-8.

22. Piedrahita RA. On the assessment of air pollution and behavior within a cookstove intervention study in Northern Ghana and development of improved measurement techniques. 2017. https://sea rch-proquest-com.proxy.library.emory.edu/docview/1904508224/ abstract/BC813B643102450CPQ/1.

23. Clasen TF, Peel J, Checkley W. Household Air Pollution Intervention Network (HAPIN) trial protocol [unpublished]

24. Burrowes V. Validation of next-generation portable pollution monitors to measure exposure to PM2.5 from household air pollution in Puno, Peru [unpublished].
25. Allen-Piccolo G, Rogers JV, Edwards R, Clark MC, Allen TT, Ruiz-Mercado I, et al. An ultrasound personal locator for time-activity assessment. Int J Occup Environ Health. 2009;15: 122-32.

26. Ruiz-Mercado I, Lam N, Canuz E, Acevedi R, Smith KR. Modeling variability in kitchen time-activity of adult guatemalan women cooking with biomass. 2010. https://www.ce.berkeley. edu/sites/default/files/news/124/ISEE-ISEA\%202010_Ilse\% 20Ruiz\%20Mercado-final\%20formated.pdf. Accessed 21 Jan 2019.

27. Balakrishnan K, Ghosh S, Thangavel G, Sambandam S, Mukhopadhyay K, Puttaswamy N, et al. Exposures to fine particulate matter (PM2.5) and birthweight in a rural-urban, mother-child cohort in Tamil Nadu, India. Environ Res. 2018;161:524-31.

28. Balakrishnan K, Sambandam S, Ramaswamy P, Mehta S, Smith KR. Exposure assessment for respirable particulates associated with household fuel use in rural districts of Andhra Pradesh, India. J Exposure Sci Environ Epidemiol. 2004;14:S14-S25.

29. Johnson M, Piedrahita R, Garland C, Pillarisetti A, Sambandam S, Gurusamy $\mathrm{T}$ et al. Exposures to PM2.5 associated with LPG stove and fuel interventions in four countries: pilot results from the HAPIN trial. ISEE Conference Abstracts. 2018. https://ehp.niehs. nih.gov/doi/10.1289/isesisee.2018.002.03.31. Accessed 29 Apr 2019.

30. Steenland K, Pillarisetti A, Kirby M, Peel J, Clark M, Checkley $\mathrm{W}$, et al. Modeling the potential health benefits of lower household air pollution after a hypothetical liquified petroleum gas (LPG) cookstove intervention. Environ Int. 2018;111:71-79. 